\title{
WOOD MOISTURE MONITORING DURING LOG HOUSE THERMAL INSULATION MOUNTING
}

\author{
P. Kotásková, Z. Havířová
}

Received: November 24, 2010

\begin{abstract}
KOTÁSKOVÁ, P., HAVÍŘOVÁ, Z.: Wood moisture monitoring during log house thermal insulation mounting. Acta univ. agric. et silvic. Mendel. Brun., 2011, LIX, No. 3, pp. 91-100

The current designs of thermal insulation for buildings concentrate on the achievement of the required heat transmission coefficient. However, another factor that cannot be neglected is the assessment of the possible water vapour condensation inside the construction.

The aim of the study was to find out whether the designed modification of the cladding structure of an existing log house will or will not lead to a risk of possible water vapour condensation in the walls after an additional thermal insulation mounting. The condensation could result in the increase in moisture of the walls and consequently the constructional timber, which would lead to the reduction of the timber construction strength, wood degradation by biotic factors - wood-destroying insects, mildew or wood-destroying fungi. The main task was to compare the theoretically established values of moisture of the constructional timber with the values measured inside the construction using a specific example of a thermal insulated log house. Three versions of thermal insulation were explored to find the solution of a log house reconstruction which would be the optimum for living purposes. Two versions deal with the cladding structure with the insulation from the interior, the third version deals with an external insulation.

In a calculation model the results can be affected to a great degree by input values (boundary conditions). This especially concerns the factor of vapour barrier diffusion resistance, which is entered in accordance with the producer's specifications; however, its real value can be lower as it depends on the perfectness and correctness of the technological procedure. That is why the study also includes thermal technical calculations of all designed insulation versions in the most unfavourable situation, which includes the degradation of the vapour barrier down to $10 \%$ efficiency, i.e. the reduction of the diffusion resistance factor to $10 \%$ of the original value.

Moreover, the dependence of the weight moisture of timber inside the insulated cladding on temperature-moisture changes in the internal and external ambient environment was examined.
\end{abstract}

$\log$ house, reconstruction, thermal insulation, wood moisture content, water vapour condensation, vapour barrier degradation

The current requirements regarding house construction in the Czech Republic lead to the reduction of energy intensiveness both of the process of construction and the following operation of the newly built houses. The potential of energy savings and the reduction of environmental load in relation to buildings is attractive especially for their considerable size, undoubted long-term character in contrast to other fields of production and services, the usage of well-known and verified technologies, and the economic attractiveness if at least a part of the potential is used, even with the current prices of energy (Tywoniak, 2005). Log houses and constructions can be considered to have a minimum impact on the environment in comparison with houses and constructions from usual materials.

The requirements concerning thermal technical properties of constructions and buildings are becoming stricter and the current Czech norm ČSN 7305 40-2 Thermal Protection of Buildings - Part 2: Requirements, does not deal with newly 
built construction only but also those where a reconstruction is conducted as the current tendency is to focus on the quality of regeneration of current buildings. This is the place where most energy is wasted, with all its negative environmental and social consequences. Therefore, the development goes in the direction of increasing the thermal resistance of the cladding, in other words reducing its heat transmission coefficient. Due to these higher thermal technical requirements, also the problem of additional thermal insulation of reconstructed buildings has to be solved when improving, reconstructing or converting current buildings. It is necessary to prepare a concept of such energyrelated modification that the building achieves a life expectancy comparable with a newly built construction after the modification. In the effort to achieve the lowest possible heat losses by reducing the heat transmission coefficient of the cladding construction and eliminating the air permeation of wooden constructions, which have their specifics, it is necessary not to interfere with their basic properties and demands laid on them (Lokaj, 2003).

In a construction where a limited condensation of water vapour is allowed inside, no amount of water vapour can remain in the annual balance of water vapour condensation and evaporation as this would permanently increase the moisture of the construction. It means, the annual amount of condensed water vapour inside the construction $M_{c, a}$ in $\mathrm{kg} /\left(\mathrm{m}^{2}\right.$.a) needs to be lower than the annual amount of evaporated water vapour inside the construction $M_{e v, a} \mathrm{v} \mathrm{kg} /\left(\mathrm{m}^{2} . \mathrm{a}\right)$. This together with the selected structure of the cladding is verified by means of calculation procedures in accordance with norm ČSN 73 0540-4.

The above mentioned facts lead to the conclusion that the mechanical strength and stability of construction, the durability of timber and woodbased materials and their resistance to biological factors cannot be guaranteed without an appropriate design of the construction structure as regards the constructional thermal technology and the evaluation of temperature and moisture conditions inside the construction (Havířová, Kubů, 2005).

The aim of the study is to compare the theoretical values of moisture content achieved by means of methods stipulated by norm ČSN 73 0540-4 with the values actually obtained by measuring inside a construction, using a specific version of a log house thermal insulation. At the same time, the dependence of the weight moisture of timber inside the insulated cladding on temperature-moisture changes in the internal and external ambient environment is examined.

\section{MATERIAL AND METHODS}

To be able to verify the results obtained by calculation methods by means of the values measured in a real building, the model building was fitted with sensors for interior temperature and air moisture, for the balance moisture in zones of the explored wood in the construction which were determined in advance, and for the external air moisture and temperature. The measurement was carried out in three succeeding winter periods.

We selected those parts of peripheral walls where the insulation effect could be most easily observed. The chosen room was a corner kitchen and a dining room, where higher relative air moisture was assumed. The walls were oriented towards northwest and northeast. The effect of sunshine on faster drying of the wood construction was thus eliminated.

\section{Thermal insulation mounting and fitting with measuring devices}

Three different versions of the cladding structure were proposed. Two of them deal with the insulation from the inside, the third deals with the external insulation. The sensors were placed into risk points where water vapour condensation was assumed in the particular version of the additional insulation (Fig. 1). We used resistance hygrometers with screw probes and temperature compensation; these were connected with an installed central board for the purpose of data registration in hourly intervals.

\section{Details and description of insulation layers}

\section{Version I}

This version is an internal thermal insulation, which corresponds to the usual design produced by designers who do not specify the type of vapour barrier in the insulation structure any closer. To thermally insulate a peripheral wall $200 \mathrm{~mm}$ thick, the thermal insulation from mineral fiber ORSIL NF, $100 \mathrm{~mm}$ thick, is proposed. The internal surface of the walls is made of gypsum board $12.5 \mathrm{~mm}$ thick. A vapour barrier - G + H Isover Difunorm foil - is inserted between the internal cladding and the thermal insulation. The thermal insulation is laid between the beams of the auxiliary construction which serves for the internal cladding mounting. For the detail of the structure see Fig. 2.

\section{Version II}

The second version resembles the previous one with the difference that the most efficient vapour barrier available in the Czech market was used. This is a polyethylene bubble foil, $4 \mathrm{~mm}$ thick, covered in aluminium film - DAPE AB. There is an air space between the vapour barrier and the internal cladding. This makes use of the reflection surface of the vapour barrier with a lower emissivity to reduce the heat transmission by eradiation. When this construction was created, it was necessary to pay attention to good quality of sealing of vapour barrier joints. 


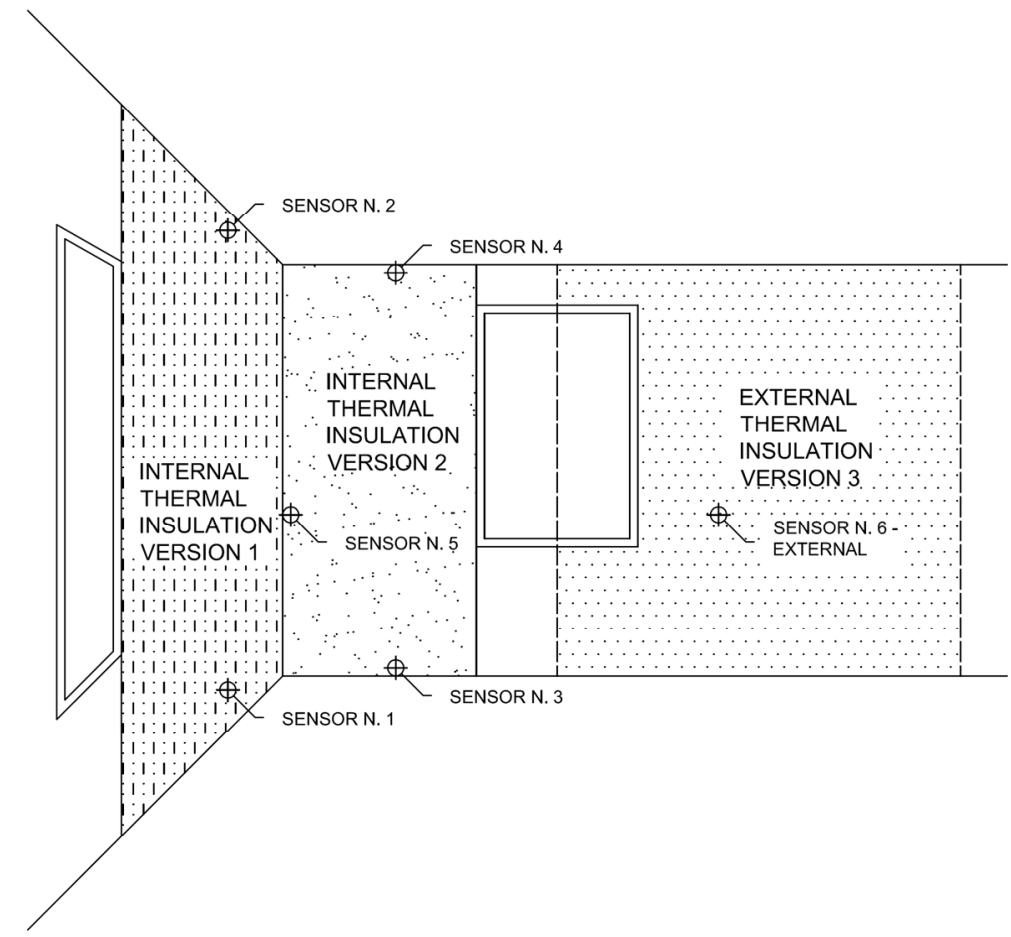

1: Location of sensors in the timber construction

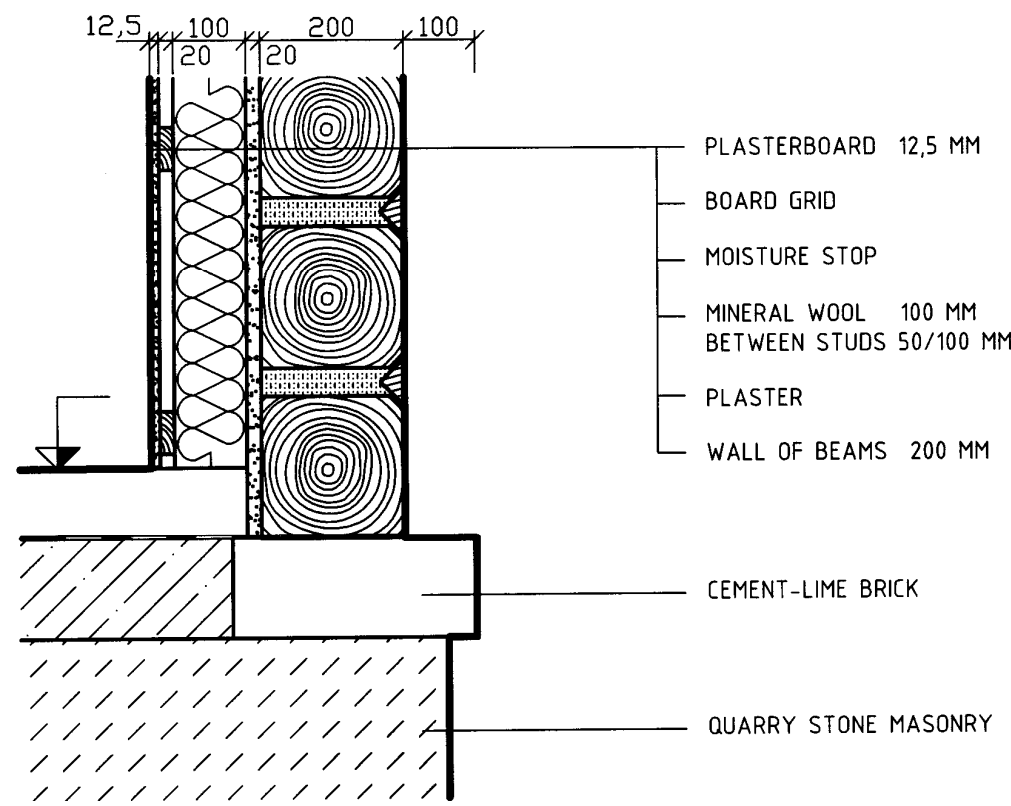

2: A detail of the thermal insulation of the log wall from interior (Version I and Version II)

\section{Version III}

This version is a construction of a peripheral wall of a log house with the additional thermal insulation mounted from the exterior. There is a diffusion foil (Dörken Delta - D) behind the log construction with a higher value of equivalent resistance $s_{d}=0.15$ $\mathrm{m}$, which creates a convection barrier. This blocks the flow of warm humid air from the interior to the thermal insulation through cracks in the plaster and the puddle of joints between the logs of the construction. The thermal insulation (Rockwool Airro) is inserted in two layers between crossing racks created from beams so that systematic heat bridges are discontinued. In front of the vented 


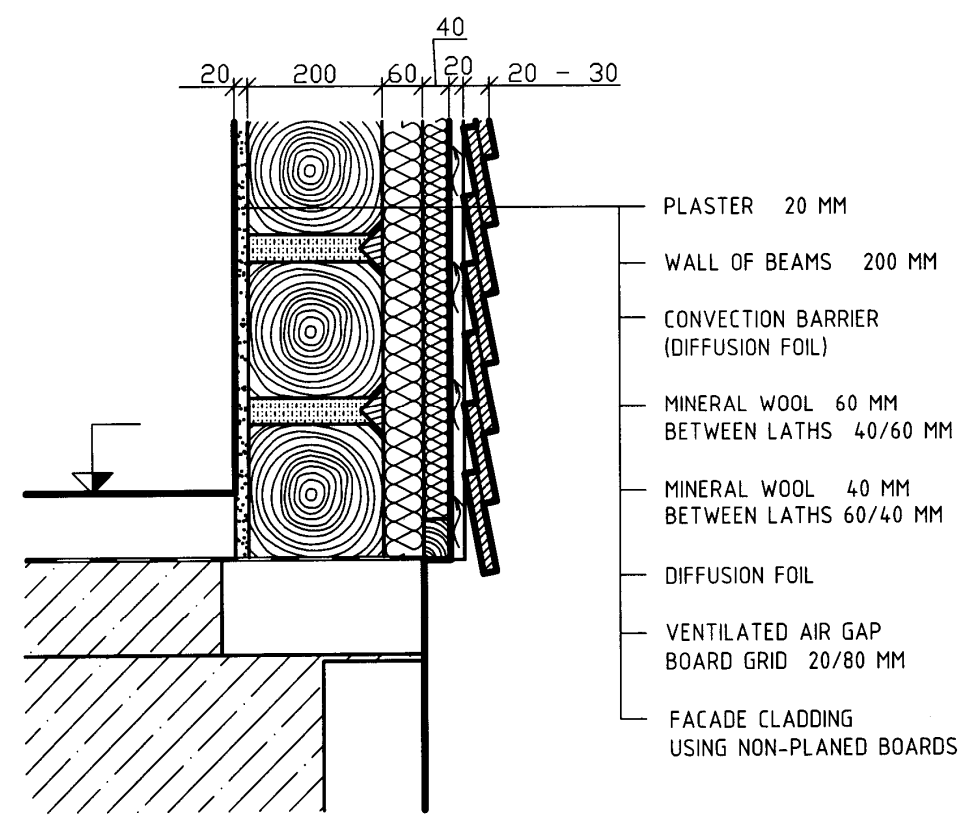

3: A detail of the thermal insulation of a log wall from exterior (Version III)

space under the external cladding from wood, a diffusion foil is proposed with an equivalent diffusion thickness of $s_{d}=0.02 \mathrm{~m}$. For the detail of the structure see Fig. 3.

\section{Data processing and evaluation}

The measured values of all periods were processed in STATISTICA CZ 9 application and the Microsoft Office Excel 2007. Especially the resulting graphs were used to choose values to compare with the computing program.

The tasks were processed using all daily measured values, for some evaluation the daily mean values were used.

Because this concerned meteorological data, the daily mean values of temperature and moisture were calculated out of the data measured in hourly intervals, as recommended by norm ČSN EN ISO 15927-1 Behaviour of Buildings Concerning Temperature and Moisture - Calculation and Presentation of Climatic Data.

To compare the individual graphs of singular data, the time series were smoothed by the STATISTICA CZ 9 application to find the average of several measurement processes in succession thanks to which the real observed value stands out. Moreover, correlation was used to determine the interdependence of the values.

The basic thermal technical evaluation of the cladding was conducted in the Svoboda software TEPLO 2010 application. For each of the proposed versions of insulation, the heat resistance and the heat transmission coefficient were calculated according to ČSN EN ISO 6946, the temperature of the internal surface, the water vapour diffusion in design conditions, and the moisture balance (without the effect of inbuilt moisture and sun radiation) according to ČSN 73 0540-4. The calculated heat transmission coefficient $U$ and the heat resistance of the construction $\mathrm{R}$ include the effect of thermal bridges which appear in the construction.

To verify the moisture relations in the construction further, we used the methodology of balance wood moisture content evaluation developed within research MSM 6215648902, part 5, stage 7 - Wooden Elements and Constructions. Energy Diagnostics of Wooden Buildings - for the solution of the "Analysis of thermal and moisture relations inside the peripheral cladding of a timber house in dependence on temperature changes in the external environment". This methodology is based on the method of the calculation of the water vapour balance in the construction according to ČSN 730540. The calculated partial pressures of water vapour and saturated water vapour in dependence on the calculation progress of temperatures in the construction are assigned with the corresponding values of balanced wood moisture content according to Čulický's nomogram (Perelygin, 1960).

To compare the calculated and the measured values the point of stability of measured values was selected in the created graphs. The values of temperature and moisture of the exterior and the interior from the point of stability were entered in the calculation as boundary conditions. The Svoboda software uses predefined boundary conditions of the internal and external air according to ČSN 73 0540, therefore, these had to be modified. 


\section{RESULTS OF MODEL BUILDING MEASUREMENT}

\section{The maximum and the minimum measured values}

The measuring was launched in 2006, when the thermal insulation was mounted. The next measuring was conducted in the following years, always during winter months. In the years in question, winters were quite mild, that is why the winter design boundary conditions stipulated by ČSN 73 0540-3 for the calculation of heat destroying insects or fungi, not even by the least demanding house fungus. Sensor 4, which reports moisture over $16 \%$ is located in the upper part of the wall and it was probably affected by other surrounding factors.

The lowest values of moisture occurred in sensor 5, where they e.g. in the third period showed values within 5.9 and $9.1 \%$. The sensor is located in the corner, i.e. in the vicinity of the fronts of long beams. We can assume that the lower value of moisture is caused by the faster drying of the beam front; therefore, this sensor was not taken into account for further comparison.

\section{SECOND PERIOD OF MEASURING}

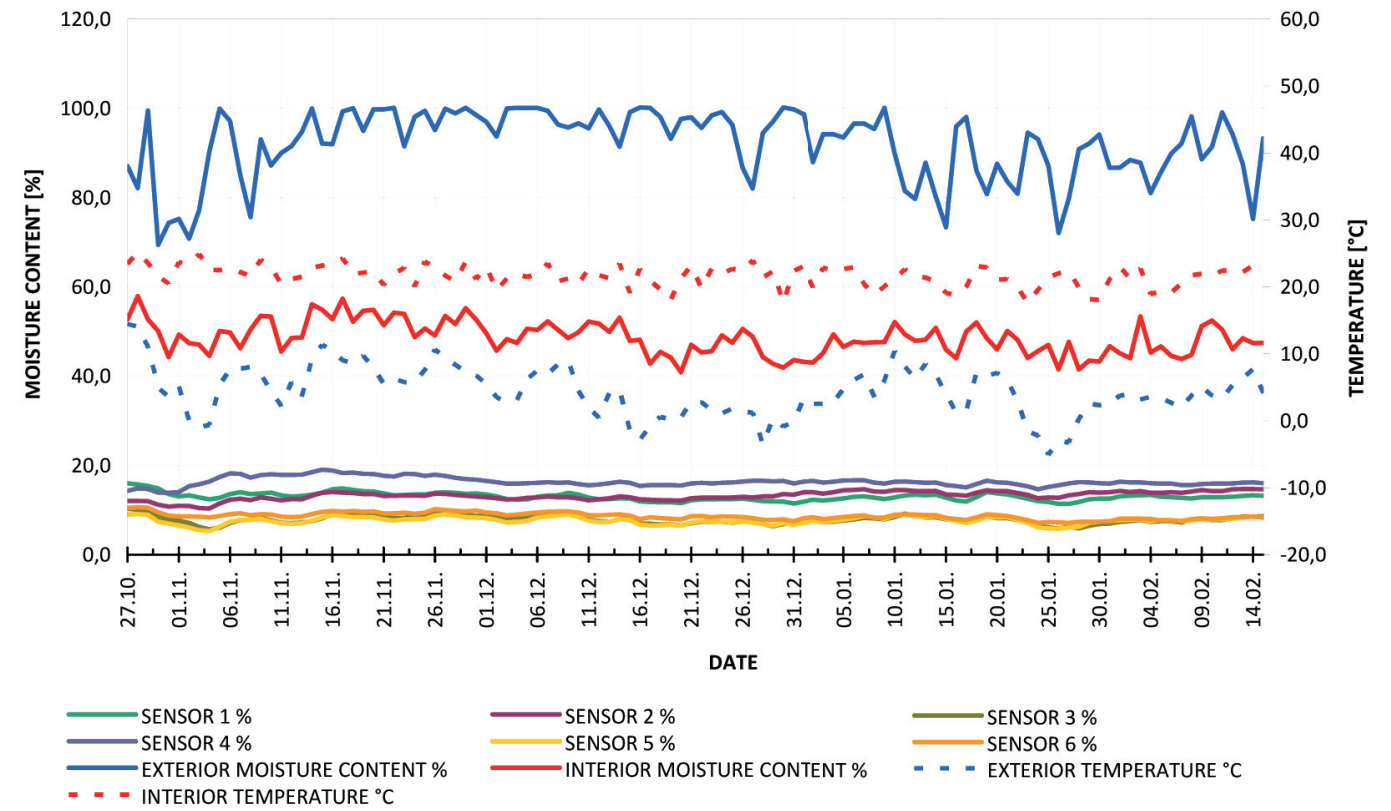

4: Wood moisture content progress of mean daily values in dependence on the temperature and moisture of the interior and the exterior for the second period of measuring

transmission and the establishment of water vapour condensation in the construction (exterior temperature $-15{ }^{\circ} \mathrm{C}$, interior temperature $+21{ }^{\circ} \mathrm{C}$ ) were not achieved.

As the presented graph shows (Fig. 4), even with a great fluctuation of the values of temperature and moisture of the interior and the exterior, the wood moisture content seems to be relatively stable. We can see based on the statistical data that the wood moisture content during the entire measured period ranges between $5.0 \%$ and $19.1 \%$, while only one sensor reports the higher moisture content. The maximum moisture content in the remaining sensors is $16.3 \%$. This means that the moisture of the timber construction is within a zone which is without any problems for wood as wood up to $16 \%$ of moisture should not be attacked by wood-

\section{Comparison of the measured and the calculated values}

To compare the values obtained through the theoretical computing model with the values measured in the real construction, the points of stability of the measured temperature and moisture were found in the graphs. The mean values from the last day at the end of a selected relatively stable period were entered as boundary conditions to the calculation. One of the periods was e.g. the time between February 4 and February 7, 2007 (Fig. 5).

Out of the values calculated for version 1 , where the insulation is internal with smaller quality of vapour barriers, diffusion resistance factor $\mu=250000$ [-] - only the results of moisture balance have been chosen for comparison: 


\begin{tabular}{|c|c|c|c|c|c|c|c|c|c|c|c|}
\hline \multicolumn{12}{|l|}{ Diffusio } \\
\hline & & & & & \multicolumn{7}{|c|}{ (without the effect of inbuilt moisture and sun radiation) } \\
\hline \multicolumn{12}{|c|}{ Progress of temperatures and pressures in design boundary conditions: } \\
\hline interface: & $\mathbf{i}$ & $1-2$ & $2-3$ & $3-4$ & 4-5 & $5-6$ & $6-7$ & $7-8$ & $8-9$ & 9-10 & e \\
\hline temp. $\left[{ }^{\circ} \mathrm{C}\right]:$ & 19.3 & 19.1 & 18.3 & 18.3 & 7.5 & 7.4 & 7.3 & 6.1 & 4.8 & 3.5 & 2.2 \\
\hline $\mathrm{p}[\mathrm{Pa}]:$ & 1056 & 1055 & 1055 & 683 & 683 & 682 & 681 & 673 & 665 & 657 & 650 \\
\hline p,sat [Pa]: & 2243 & 2206 & 2097 & 2097 & 1033 & 1029 & 1026 & 938 & 858 & 783 & 715 \\
\hline $\mathrm{RHx}$ [\%] & & & & & 32.6 & 66.1 & 66.4 & 71.7 & 77.5 & 83.9 & 90.9 \\
\hline$\omega x[\%] \sim$ & & & & & 6.5 & 12.7 & 12.8 & 13.4 & 15.2 & 18.8 & 22.0 \\
\hline
\end{tabular}

Note:

$\mathrm{RHx}$ is relative air moisture $\omega \mathrm{x}$ is an approximate value of wood moisture content

The measured weight moisture [\%] sensor 1

\section{2. - 9. 2. 2007}

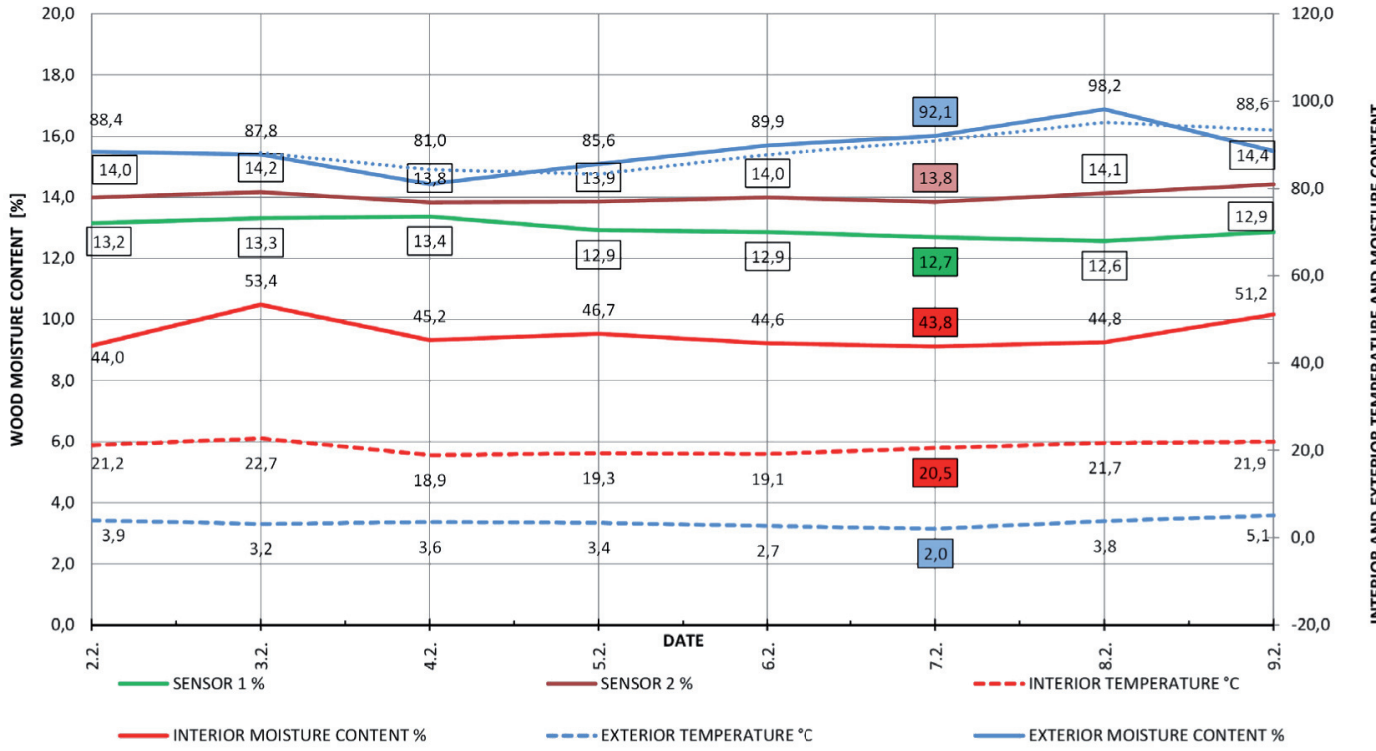

5: Wood moisture content progress from mean daily values measured at sensors 1 and 2 in dependence on the temperature and moisture of the interior and the exterior for the selected stable period

Sensors 1 and 2 installed for the first version of thermal insulation are located on the internal surface of a $\log$ wall beam in calculation area 7 . The sensor electrodes are inserted $20 \mathrm{~mm}$ deep in the beam. It means that the sensor takes the integral moisture of the internal surface $20 \mathrm{~mm}$ layer, whereas the calculation establishes the corresponding balance moisture of the beam surface, i. e. interface 6-7 (highlighted in red). The comparison of the measured and the calculated values leads to the conclusion that the measured values, which can be affected by other surrounding factors, are nearly the same as the calculated values. The mean value ranges within the calculated range through interfaces 6-7 and 7-8, i.e. the internal beam surface and the moisture of wood $50 \mathrm{~mm}$ deep.

The calculation for the comparison of version 2 in the same periods is based on the structure for version 2 and the same boundary conditions. The designed structure includes a high quality vapour barrier with the diffusion resistance coefficient $\mathrm{m}=347,000$ [-].

The differences in values measured for version 2 at sensor 4 are slightly higher, which can be caused by e. g. thermal bridges near the ceiling construction because sensor 4 is placed in the risky top part of the wall. By comparing the mean value of weight moisture as measured in both sensors with the calculated values, we obtain better results. 
For version 3, where the insulation is mounted from the exterior, we used sensor 6 for comparison. The mean value of measured values is lower than the calculated values with the difference of several tenths.

The results clearly show that the measured values of wood moisture content are comparable with the calculated values. The measured values are lower than the calculated ones, which means that the calculation is on the safe side.

\section{The results of calculations with norm values of boundary conditions of the exterior and the interior environment}

Although the measured values present no risk for the insulated walls, it is necessary to verify this by a calculation using the norm boundary conditions according to ČSN 73 0540-3. The results will show how the wall would behave in extreme conditions, especially the exterior air temperature. The calculation of the timber construction reliability assessment is always accompanied by a graph.

The graph (Fig. 6) and the calculation for version 1 make it obvious that a condensation zone is created within the wood.

Amount of condensed water vapour $\mathrm{M}_{\mathrm{c}, \mathrm{a}}$ : $0.002 \mathrm{~kg} / \mathrm{m}^{2}$ per year.

Amount of evaporating water vapour $\mathrm{M}_{\mathrm{ev} 2}$ : $0.123 \mathrm{~kg} / \mathrm{m}^{2}$ per year.

The condensation appears at exterior temperature below $-5{ }^{\circ} \mathrm{C}$, which is about 48.5 days a year according to ČSN 73 0540-3. In consequence of the mentioned conditions, the balance wood moisture will increase in the current timber wall.
As we can often encounter damage to or a low quality of vapour barrier layer in the practice, the next step takes into account vapour barrier degradation. Some authors recommend an expert estimate to decrease the diffusion resistance coefficient $\mu$ down to $10 \%$ of its original value in dependence on the degree of the disintegration of the vapour barrier layer homogeneity. The following calculation used the same input data, only the diffusion resistance value was decreased from the original $\mu=250,000$ to $\mu=25,000$.

The results and the graph reveal that the vapour barrier degradation leads to the condensation within the designed structure of construction.

Amount of condensed water vapour $\mathrm{M}_{\mathrm{c}, \mathrm{a}}$ :

$0.041 \mathrm{~kg} / \mathrm{m}^{2}$ per year.

Amount of evaporating water vapour $\mathrm{M}_{\mathrm{ev}, \mathrm{a}}$ : $0.898 \mathrm{~kg} / \mathrm{m}^{2}$ per year.

Condensation appears at outside temperature below $0.0^{\circ} \mathrm{C}$.

Although the balance of condensed and evaporating vapour shows that the amount of condensed water vapour is lower than $0.1 \mathrm{~kg} / \mathrm{m}^{2}$ a year and the annual amount of evaporating vapour is larger than the amount of condensed vapour, this structure has to be considered risky as the outside air temperatures of $0{ }^{\circ} \mathrm{C}$ and lower, at which condensation occurs, appear for approximately 130 days a year.

In the second version of insulation we can see that in a construction with a high quality vapour barrier no condensation of water vapour will appear at boundary conditions for rooms designed for living. At outside air temperatures around $-15^{\circ} \mathrm{C}$ and a damaged vapour barrier the beams of the current

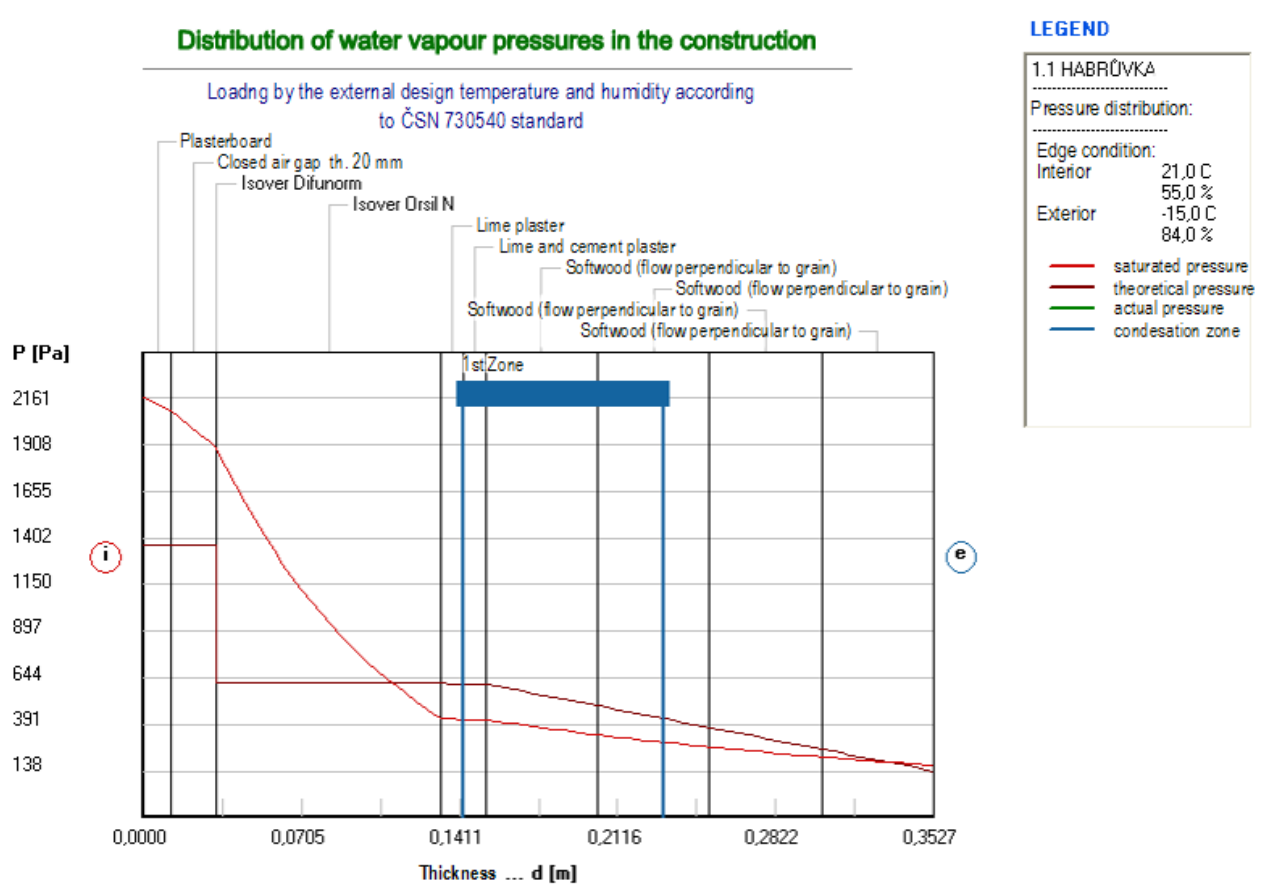

6: Distribution of water vapour pressures in a typical place of the construction for calculation 1.1-Habrivva Version $1\left[\mu_{\text {vapourbarrier }} 100 \%, \mu_{\text {wood }} 157(-)\right]$ 
timber wall can moisten over the value of balance moisture of $20 \%$. In conditions corresponding to boundary conditions for bathrooms, the balance wood moisture content in the construction of eripheral wall will logically rise more. Moreover, the timber in the current log construction will be exposed to direct weather influences, which can have a negative impact on further wood moistening and the durability of the construction, especially from the northern side of the building with no sunshine.

In the third version of insulation, where the insulation is external, the structure includes a vented gap between the insulation and the facade cladding, which should allow for the drying of moisture of the surface layer by the circulating air.

The graph of the water vapour pressures (Fig. 7) shows that no area of condensation appears in

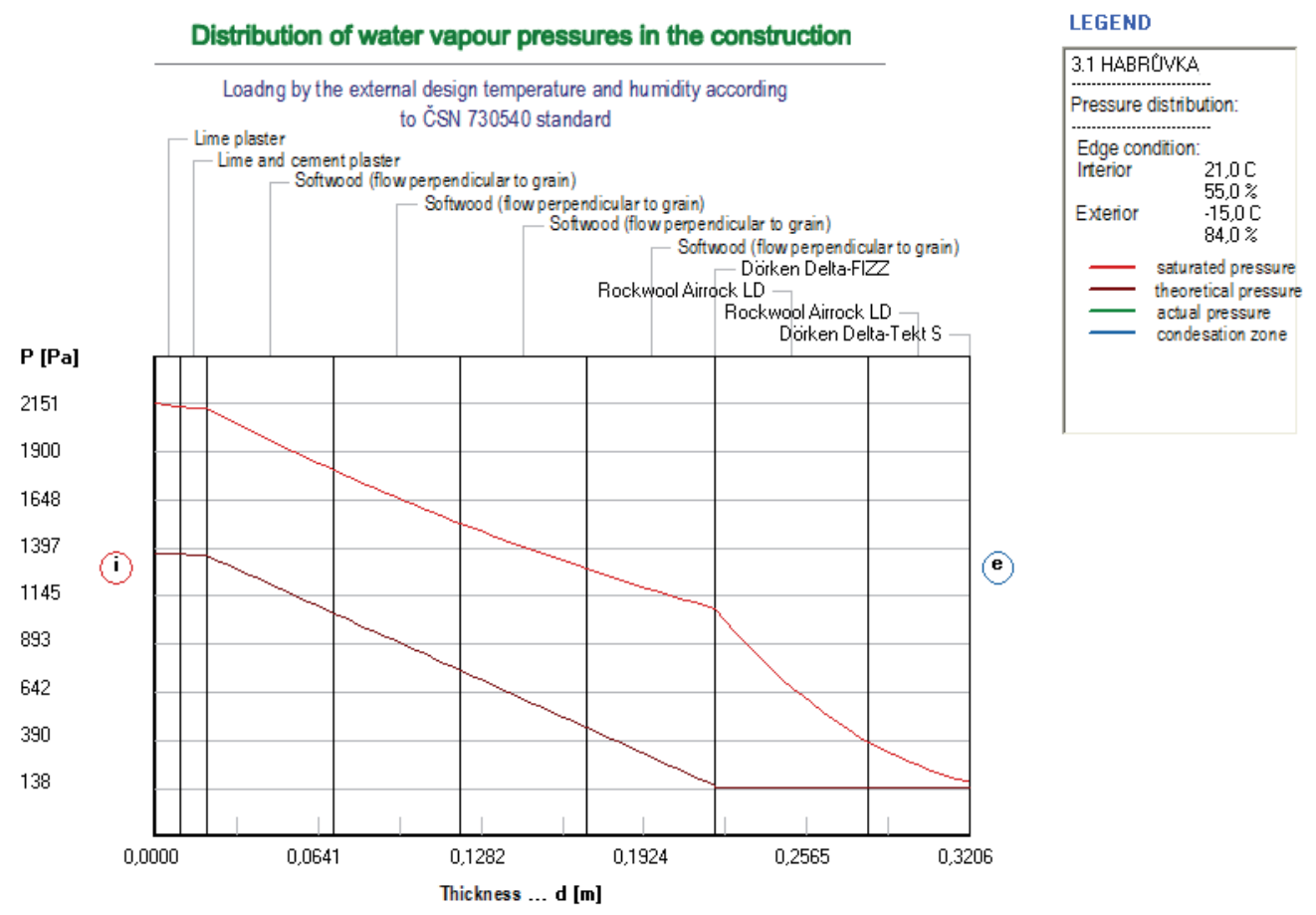

7: Distribution of water vapour pressures in a typical place of the construction for calculation 3.1-Habrioka Version 3 $\left[\mu_{\text {vapourbarrier }} 100 \%, \mu_{\text {wood }} 157(-)\right]$
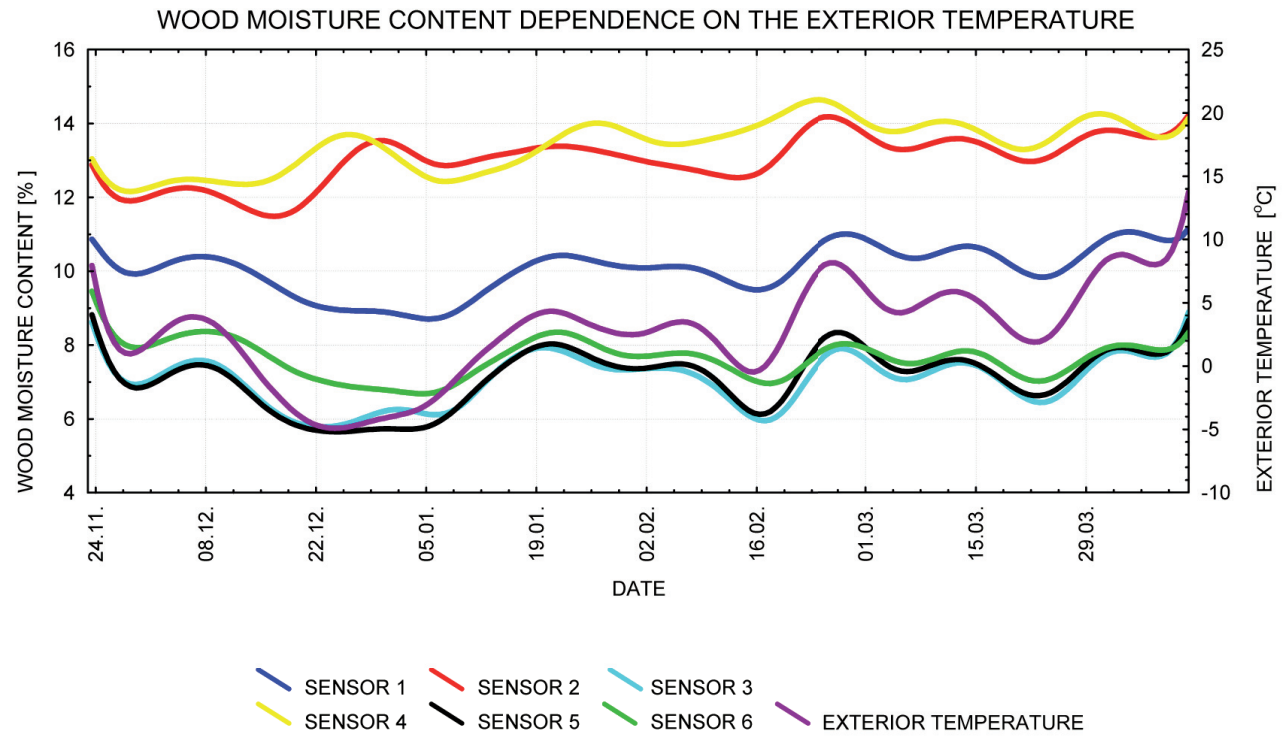

8: Wood moisture content dependence on the exterior temperature 
the construction. The calculation reveals that the balance wood moisture content is very low; the current timber construction is thus protected against mildew, wood-destroying fungi and wood-destroying insects. The designed structure of the peripheral wall construction of the log house with additional thermal insulation from the external side effectively meets the principles of wood constructional protection. Moreover, the timber construction is protected against unfavourable weather conditions.

The correlation of the individual periods of measurement and the graphs show that it is the temperature of the exterior which has the greatest impact on the moisture in the wood of the construction. This dependence can also be observed from the following graph (Fig. 8), where the individual time series were smoothed out to make the dependence more obvious.

Based on a detailed analysis of the values presented in the graphs, we can state that shortterm fluctuation of temperatures and moisture in the exterior and the interior have no essential effect on the changes in wood moisture content. The wood moisture content is mainly affected by long-term changes in the internal and the external environment.

\section{DISCUSSION}

When mounting additional thermal insulation, it is always necessary to consider carefully whether the building should be insulated from the external side which disrupts the appearance, or from the internal side which brings about a higher risk of water vapour condensation inside the construction with possible following wood moisture increase over $20 \%$. As both the calculations and measurement confirmed, it is necessary to use high quality materials for the structure of the cladding so that the increase in thermal-insulation properties of peripheral walls does not lead to the decrease in their reliability and durability. At the same time, it is important to make sure all technological processes are followed carefully.

\section{SUMMARY}

To explore the possible solutions of an additional thermal insulation of a building which serves for living, the reconstruction of which has to meet technical requirements of new regulation no. 268/2009 Coll., a log house - a gamekeeper's lodge, was selected as a model building. Three versions of thermal insulation structure for the cladding were mounted and monitored for the period of three years. The main phenomenon monitored was the moisture content of the constructional timber. Two of the versions deal with an internal insulation, the third version is an external insulation. The main task was to find out whether the designed modification of the cladding structure leads to the condensation of water vapours, which would result in inadequate wood moisture. Increase in wood moisture could lead to wood degradation and the degradation of the entire building or the decrease in its durability. The values of wood moisture in individual layers calculated by means of calculation methods stipulated by norm ČSN 73 0540-4 were compared with the values really measured inside the construction in each specific version of the insulation.

The assessment of the proposed versions of thermal insulation structure of the peripheral log walls reveals that a proper dimensioning of wood-based constructions has the essential influence on their durability and functional reliability. It is obvious that especially a wrong choice of materials and breach of technological procedures during mounting have a highly negative effect. The results and the graphs show that due to the degradation of the vapour barrier, condensation of water vapours occurs inside the proposed structure. The highest risk of increased moisture caused by e.g. vapour barrier degradation, which can be among others caused by inaccuracies during mounting but also in the time of usage, is connected with the thermal insulation implemented from the inside.

Based on the assessment of the thermal insulation structure of a construction, we can conclude that an additional thermal insulation of log houses from the interior is practically always risky. Moreover, the timber wall is exposed to the weather and is not protected against rainwater leaking into drought cracks. On the contrary, we can state that the proposed thermal insulation of peripheral walls of the $\log$ house from the exterior can guarantee mechanical resistance and stability, thermal protection of the building and energy savings.

The comparison of the measured and the calculated values reveals that short-term fluctuations of temperatures and moisture in the exterior and the interior have no essential effect on the changes in the wood moisture content. The wood moisture content is mainly affected by long-term changes in the temperature and moisture of the internal and the external environment. The correlation of the individual periods of measurement and the graphs shows that the temperature of the exterior has the greatest impact on the moisture in the wood of the construction. 


\section{Acknowledgement}

The work was supported by research plan of the Ministry of Education, Youth and Sports of Czech Republic No. MSM 6215648902.

\section{REFERENCES}

HAVÍŘOVÁ, Z., KUBU゚, P., 2005: Reliability and service life of wood structures and buildings. Acta universitatis agriculturae Mendelinae Brunensis. Brno, MZLU. ISSN 1211-8516.

LOKAJ, A., 2003: Ověrení funkčnosti komponenti̊ dřevéných konstrukcí. Sborník konference se zahraniční účastí „DREVO - surovina 21. storočia v architektúre a stavebníctve". Smolenice 10.11. 9., p. 27-30. ISBN 80-89145-01-9.

TYWONIAK, J., 2005: Nízkoenergetické domy. Principy a príklady. Praha, Grada Publishing. ISBN 80-2471101-X.

ČSN 7305 40-2, 2002: Tepelná ochrana budov - Část 2: Požadavky. Praha: Český normalizační institut.

Address

Ing. Pavla Kotásková, Ústav tvorby a ochrany krajiny, doc. Dr. Ing. Zdeňka Havířová, Ústav základního zpracování dřeva, Mendelova univerzita v Brně, Zemědělská 1, 61300 Brno, Česká republika, e-mail: pavlakot@mendelu.cz, havirova@mendelu.cz 